\title{
Performance study of an industrial RO plant for seawater desalination
}

\author{
João Abel G.C.R. Pais, Licínio Manuel G.A. Ferreira* \\ Department of Chemical Engineering, University of Coimbra, Pólo II, Pinhal de Marrocos, \\ 3030-290 Coimbra, Portugal \\ Tel.+351 (239) 798745; Fax: +351 (239) 798703; email: lferreira@eq.uc.pt
}

Received 7 February 2006; Accepted 7 June 2006

\begin{abstract}
In this work, an approach to study the long-term performance of an industrial water desalination plant is described. Operational data corresponding to the time period of 454 days were analysed and from the results obtained it was found that the normalized water permeability coefficient declined by about $7 \%$. Due mainly to the temperature effects, the salt permeability coefficient exhibit significant changes only during the summer period. The equations used allowed a good description of the performance of the plant.
\end{abstract}

Keywords: Reverse osmosis; Desalination; Permeability coefficient; Performance

\section{Introduction}

Reverse osmosis (RO) is a separation process for water desalination which has some advantages in terms of saving energy, modularity, flexibility, ability to construct small size plants or even less installation space when compared to other traditional techniques, which include namely thermal processes, such as the multi-stage flash (MSF) distillation [1,2]. In the RO process, a semipermeable membrane is used for separation of

*Corresponding author. particles sizes of $5 \times 10^{-3}-1 \times 10^{-4} \mu \mathrm{m}$, including single charge ions as such $\mathrm{Na}^{+}$and $\mathrm{Cl}^{-}$[3]. The separation is driven under high pressures, not more than 7.0 MPa for most of commercially available RO membranes [1] in which the fluxes of water and salt through the membrane are considered viable economically, at industrial scale, if the operation is carried out at pressures 50 to $100 \%$ higher than the transmembrane osmotic pressure.

In the desalination, variables such as the permeate (purified water) quantity and quality 
should be maximized for the most efficient and economical use of the process. Therefore, it is important to evaluate the decline of those characteristics, due to the membrane compaction and fouling, using long-term operational data [4,5]. In this work, data corresponding to 454 day of operation of one RO unit included in an industrial desalination plant were examined. It was demonstrated that the evolution of water and solute permeability coefficients are good indicators for evaluating the performance of the membranes used in the unit.

\section{Plant description}

The plant is located in the island of Porto Santo, an island of the Madeira Archipelago (Portugal), which includes $4 \mathrm{RO}$ units with total capacity of $6800 \mathrm{~m}^{3} / \mathrm{d}$, from which $1500 \mathrm{~m}^{3} / \mathrm{d}$ corresponds to unit 1 that was considered in our study. This unit started to run in February 2003 and has operated continuously. The unit utilize spiral wound Koch membranes and operate at 5065 bar. Fig. 1 shows a schematic diagram of the seawater desalination process in the unit 1. It consists of four major components as follows: (1) advanced pre-treament in which untreated water after to be filtered in sand bed is pumped from subterranean galleries to the suface; (2) conventional pre-treatment consisting of sulfuric acid dosing and microfiltration with cartridge filters of $5 \mu \mathrm{m}$; (3) RO unit composed of 24 pressure vessels in parallel, each one of them containing three spiral wound (Koch membranes of the type TFC 28323 SS-465 Magnum) modules; (4) posttreatment of the permeate.

\section{Theory}

\subsection{Basic equations}

A semi-empirical model [6] suitable for designing reverse osmosis units (Eqs. 1-2) was used to calculate the average values of the apparent rejection factor and salt $(\mathrm{NaCl})$ concentration in the bulk feed water, $\bar{c}_{21}$, as follows:

$$
\begin{aligned}
& R=1-\ln \left[1-S \frac{\bar{c}_{23}}{c_{21 \mathrm{E}}}\right] /[\ln (1-S)] \\
& \bar{c}_{21}=c_{21 \mathrm{E}}\left[\frac{1-(1-S)^{1-R}}{(1-R) S}\right] .
\end{aligned}
$$

where $c_{21 \mathrm{~F}}$ is the solute concentration of the feed, $\bar{c}_{23}$ is the average salt concentration of the permeate, and $S$ is the recovery factor $\left(S=q_{\mathrm{P}} / q_{\mathrm{F}}\right.$, where $q_{\mathrm{P}}$ and $q_{\mathrm{F}}$ are permeate and feed flowrates, respectively).

The average value of the real rejection factor, $R^{\prime}$, was estimated from the modified Eq. (1) as given below:

$$
R^{\prime}=1-\ln \left[1-S \frac{\bar{c}_{23}}{\bar{c}_{22}}\right] /[\ln (1-S)]
$$

where $\bar{c}_{22}$ is the average solute concentration at the high pressure side of the membrane.

A material balance within the boundary layer that considers convective mass transfer of the salt towards the membrane and diffusive mass transfer of the salt away from the membrane (Eq. 4) yields the relationship between the concentration polarization and permeate flux:

$$
\frac{\bar{c}_{22}-\bar{c}_{23}}{\bar{c}_{21}-\bar{c}_{23}}=\exp \left(\frac{J_{\mathrm{P}}}{k_{2}}\right)
$$

The average volumetric flux of the permeate, $J_{\mathrm{P}}$, was evaluated from the permeate fowrate values measured and the mass-transfer coefficient, $k_{2}$, was estimated using Eq. (5) [7]:

$$
S h=0.080 R e^{0.875} S c^{0.25}
$$




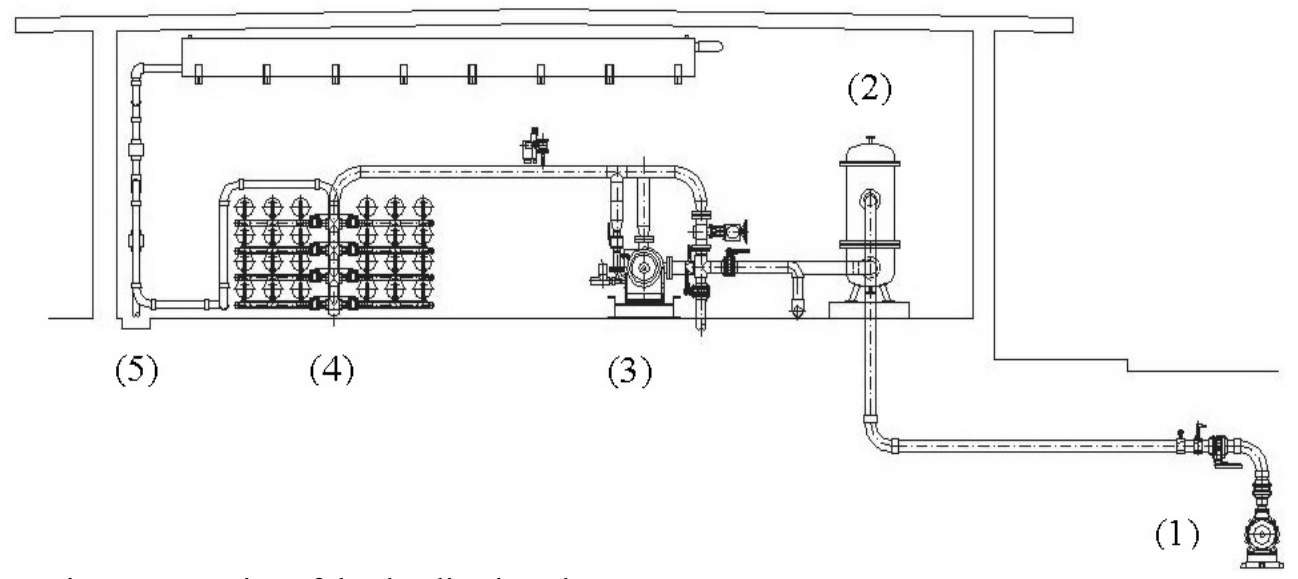

Fig. 1. Schematic representation of the desalination plant.

where $S h, R e$ and $S c$ are the Sherwood, Reynolds and Schmidt numbers, respectively.

Using Eq. (4) it is possible to estimate $\bar{c}_{22}$, then, according the Eq. (3), the average real rejection factor may be calculated.

The solution diffusion mass transfer model was used to calculate the average water and salt permeability coefficients $A$ and $B_{2}$, as follows:

$$
\begin{aligned}
& J_{P}=A(\Delta \bar{P}-\Delta \bar{\Pi}) . \\
& j_{2}=B_{2}\left(\bar{c}_{22}-\bar{c}_{23}\right) .
\end{aligned}
$$

where $j_{2}$ is the average mass flux of the solute.

The effect of the temperature on the water permeability factor [7] was evaluated by Eq. (6).

$$
F C T=A_{\mathrm{T}} / A_{25}=\exp [0.0299(T-25)] .
$$

\subsection{Physical properties}

For solving the previous equations, the following properties of the seawater were used: density, viscosity, osmotic pressure and diffusivity. The density [8] was calculated by:

$$
\rho=498.4 m+\sqrt{248400 m^{2}+752.4 c m}
$$

where $c$ is the total concentration of salts (salinity) and

$$
m=1.0069-2.757 \times 10^{-4} T
$$

From the Stoughton and Lietke's correlation [9], we estimated the osmotic pressure,

$$
\pi=4540.47 C^{0.985}
$$

in which $C$ is the molality of all dissolved ions and nonionic species in the solution.

The viscosity and diffusivity were calculated by the following formulas [8]:

$$
\eta=1.234 \times 10^{-6} \exp \left(0.00212 c+\frac{1965}{273.15+T}\right)
$$

$$
\begin{aligned}
D_{2} & =6.725 \times 10^{-6} \\
& \exp \left(0.154 \times 10^{-3} c_{2}-\frac{2513}{273.15+T}\right)
\end{aligned}
$$

where $c_{2}$ is the salt concentration. 


\section{Results and discussion}

Operational data taken from the online measurements and that covered a period of 454 days were considered in our study. These data included: $\mathrm{pH}$ values of the feed and permeate streams, feed temperature at inlet of the pressure vessels, applied pressure differences, flowrates and condutivities of the feed and permeate. Other data were also supplied from the chemical and physical analysis of samples collected on a biweekly basis. These analyses involved the sampling of 6 streams in the plant, namely the feed from 4 subterranean galleries, the pre-treated water and the permeate solution. The data concerning the one typical analysis of water taken from one subterranean gallery, performed during the first semester of 2003, are summarized in Table 1.

Table 1

Chemical and physical characteristics of water obtained from a subterranean gallery

$\begin{array}{ll}\mathrm{pH} & 7.8 \\ \text { Conductivity at } 25^{\circ} \mathrm{C} & 54,870 \mu \mathrm{S} \cdot \mathrm{cm}^{-1} \\ \text { Total hardness } & 6191 \mathrm{mg} \cdot \mathrm{L}^{-1} \mathrm{CaCO}_{3} \\ \text { Total alkalinity } & 175 \mathrm{mg} \cdot \mathrm{L}^{-1} \mathrm{CaCO}_{3} \\ \text { Concentration of species: } & \\ \quad \mathrm{Cl}^{-} & 20.31 \mathrm{~kg} \cdot \mathrm{m}^{-3} \\ \mathrm{Na}^{+} & 11.32 \mathrm{~kg} \cdot \mathrm{m}^{-3} \\ \mathrm{SO}_{4}^{2-} & 2.82 \\ \mathrm{Mg}^{2+} & 1.36 \\ \mathrm{Ca}^{2+} & 0.42 \\ \quad \mathrm{~K}^{+} & 0.41 \\ \mathrm{HCO} & 0.22 \\ \mathrm{TDS} & 37.01\end{array}$

We used suitable correlations to convert conductivity to salinity expressed in ppm, for the feed and permeate streams, in which their respective conductivities were given real time from insitu measurements and corrected for $25^{\circ} \mathrm{C}$. The determination of the mass concentrations of chloride and sodium in several samples collected from the 4 streams allowed to verify that the contribution of those two ions together was practically constant in all of them and represented a value identical in magnitude to that found in seawater - $85.65 \%$ of all dissolved salts [10]. The analyses of the pre-treated stream also revealed that the treatment with acid sulfuric did not change significantly the proportion of the major constituents $(\mathrm{Na}$ and $\mathrm{Cl}$ ) with respect to the salinity. Thus, assuming the proportion was representative of the composition of sodium chloride in the feed stream, it was possible to calculate $c_{21 F}$ in ppm.

The average salt concentration of the permeate $\bar{c}_{23}$ was evaluated considering the summation of the mass concentrations of chloride and sodium regardless the salinity was nearly constant and corresponded to $92.2 \%$. This proportion was observed in all chemical analyses done to the permeate stream.

Fig. 2 ilustrates the evolution of the feed temperature with time; the higher variation which occurred during the summer months was of $6.3^{\circ} \mathrm{C}$. The temperature change did not influence directly the feed water salinity as shown in Fig. 3. From this figure can be observed that the average feed concentration was of 37,200 ppm with a variation lesser than $4 \%$. It should be also mentioned that the temperature indirectly affects the permeate quality (see Fig. 4) and intrinsec membrane parameters such as the water and salt permeability coefficients, $A$ and $B_{2}$. The evolution of the coefficients $A$ and $B_{2}$ calculated using Eqs. (1)-(6) as a function of time are shown in

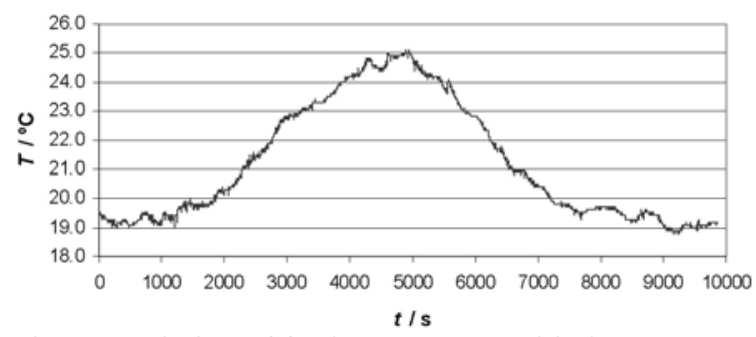

Fig. 2. Evolution of feed temperature with time. 


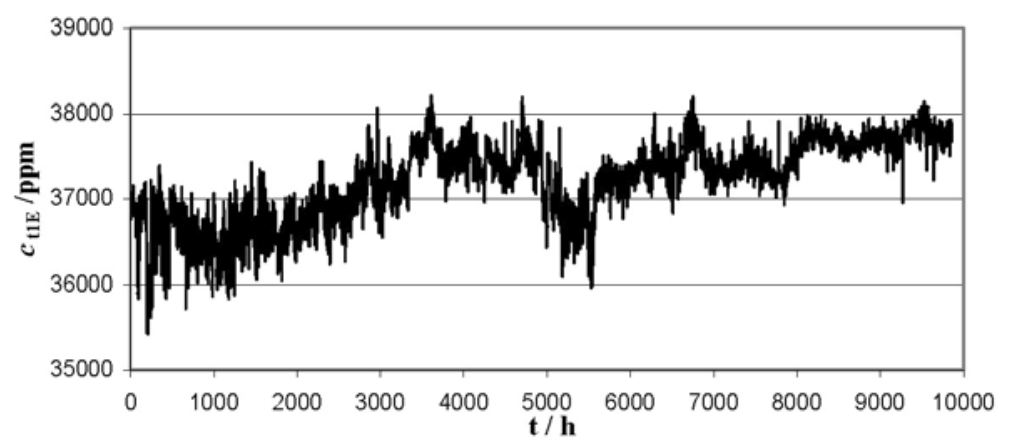

Fig. 3. Evolution of feed water salinity with time.

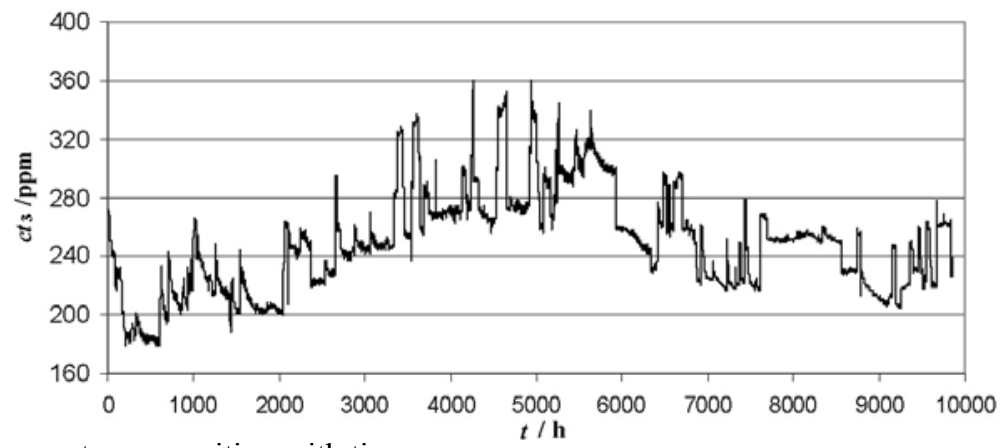

Fig. 4. Evolution of permeate composition with time.

Figs. 5-7. In Fig. 5 are plotted two curves corresponding to the variations of the water permeability coefficient considering the temperature effect (grey line) and using the correction factor (dark line) given by Eq. (8). Based on an estabilization period of the membranes, at about of 30 days after starting the plant operation, we calculated an average permeability coefficient, $A_{720}$, equal to $2.45 \times 10^{-7} \mathrm{~m}^{3} \cdot \mathrm{m}^{-2} \cdot \mathrm{s}^{-1} \cdot \mathrm{bar}^{-1}$. Next, the ratio $A_{25}$ (coefficient corrected for $25^{\circ} \mathrm{C}$ ) $/ A_{720}$ values were obtained and plotted in Fig. 6. In this figure can also be seen that the exponential expression $A_{25} / A_{720}=0.994 \exp \left(-6.0 \times 10^{-6} t\right)$ fits with reasonable accuracy the trend of the data. For the operational time studied (454 days), a decrease not more than $7 \%$ in the value of the normalized water permeability coefficient $\mathrm{A}_{25} / \mathrm{A}_{720}$ was found.

The salt permeability coefficient $B_{2}$ significantly changed as shown in Fig. 7; it was mainly influenced by the temperature, as mentioned before, and also in much lesser extent by pressure changes. Indeed, higher $B_{2}$ values were observed during the summer period in which the plant processed more high feed temperatures having as consequence the increase of the salt passage through membrane. Obviously this effect changed the permeate characteristics without compromising its quality that was maintained well within specifications. The plant has produced drinkable water with a salt concentration that is below the maximum allowed by the Portuguese legislation (Law no. 243/2001) - 200 and $250 \mathrm{mg} / \mathrm{L}$ for sodium and chloride ions, respectively.

Another parameter of practical interest is the specific energy consumption, $S E C$. The average values of this parameter corrected for $25^{\circ} \mathrm{C}$, $S E C_{25}$, were calculated dividing the input power, involving a time interval corresponding to two 


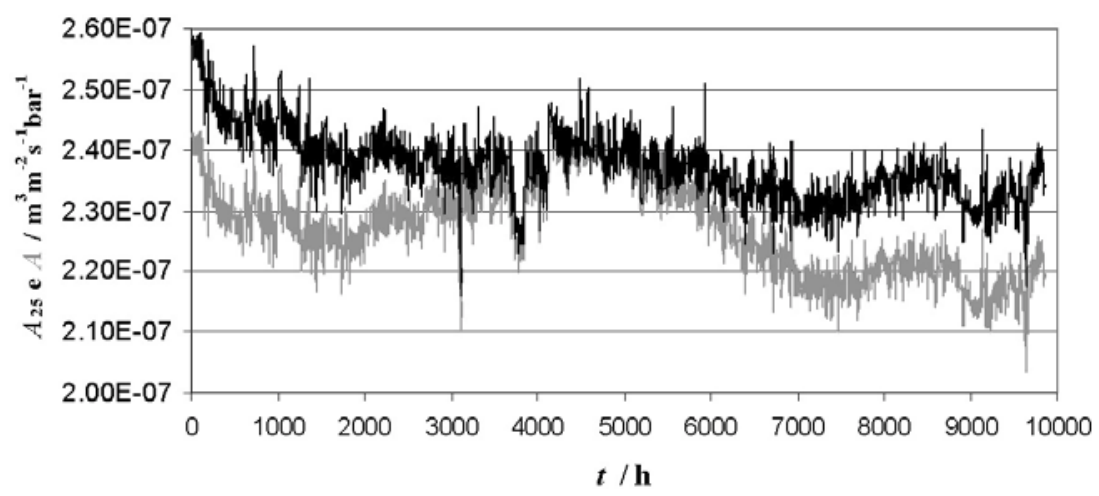

Fig. 5. Variation of hydraulic permeability coefficient with time.

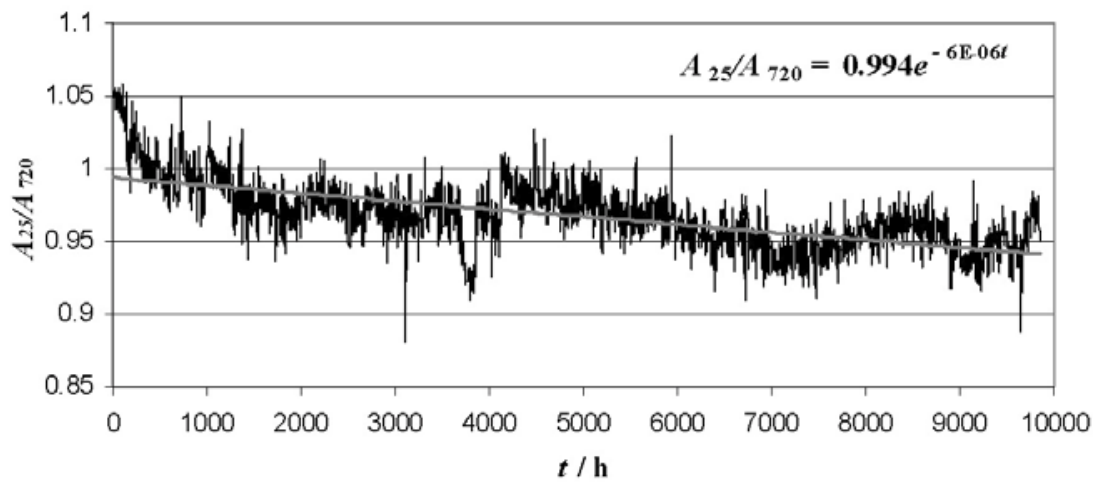

Fig. 6. Decline of normalized hydraulic permeability coefficient with time.

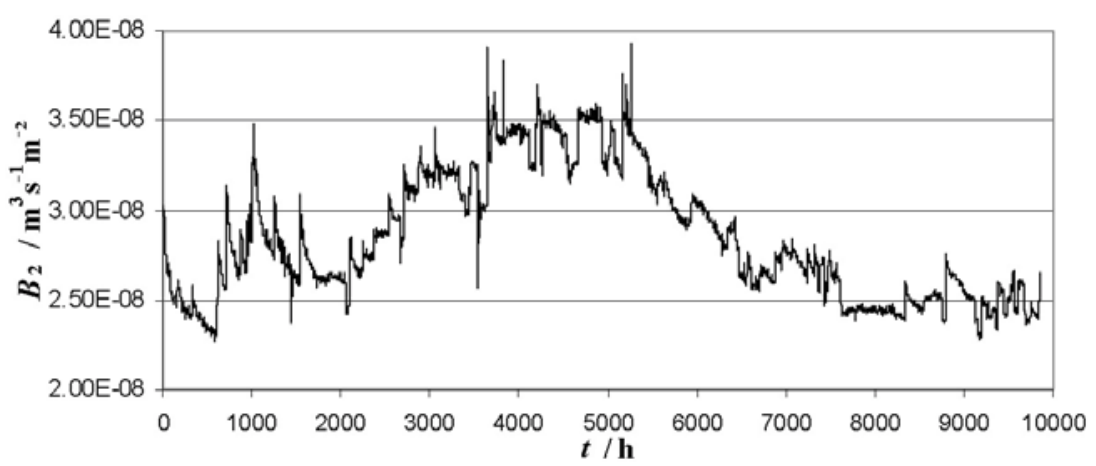

Fig. 7. Variation of salt permeability coefficient with time.

consecutive recorded data, by the permeate production estimated from $\mathrm{A}_{25}$ values presented in Fig. 5. The variations of the specific energy consumption, $S E C_{25}$, over the period time analyzed are shown in Fig. 8. These variations caused mainly by change pressures were lesser than $15 \%$ having as reference the average value calculated of $4.2 \mathrm{KWh} . \mathrm{m}^{-3}$. It was indeed observed that the energy requirements increased when the plant operated at higher operating pressures.

From the permeate flowrates for $25^{\circ} \mathrm{C}$ we also 


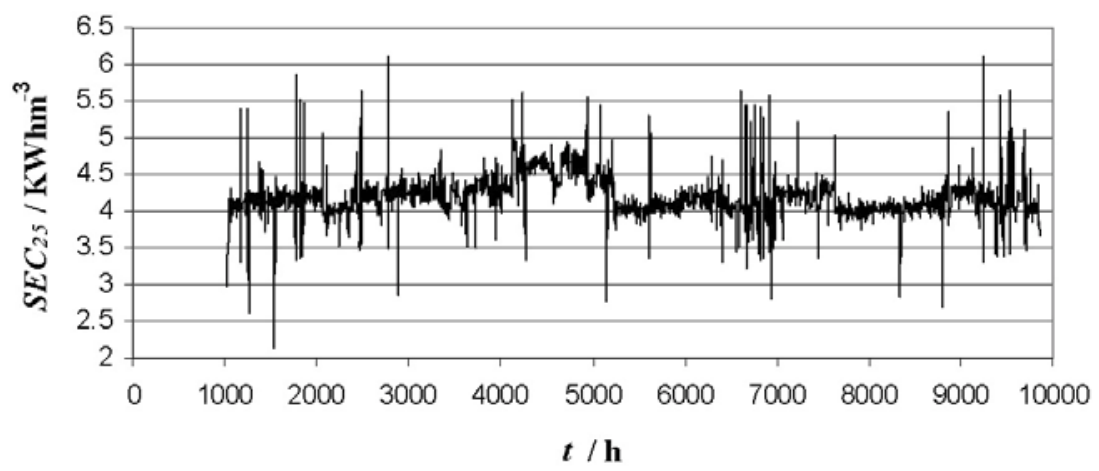

Fig. 8. Variation of specific energy consumption (SEC) with time.

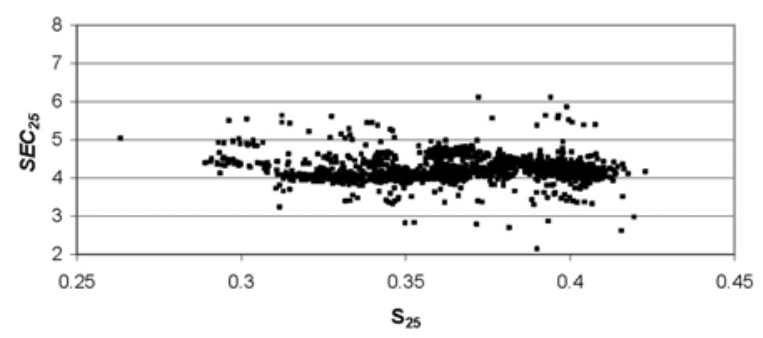

Fig. 9. Variation of specific energy consumption with factor recovery, both corrected for $25^{\circ} \mathrm{C}$.

calculate the recovery factors $\mathrm{S}_{25}$, having been found that $S_{25}$ varied between 0.29 and 0.42 . The recovery and permeate rate are two important variables that determine the hydraulic envelope of the RO system, defined as the area bounded by all the extreme operating conditions that are allowed for a specific plant. Manth et al. [11] reported that the specific energy consumption decreases when the plant operates with hydraulic components like the feed water conditions more favorable (higher temperature and/or lower salinity) or vice-versa. Moreover, those authors also referred that the $S E C$ is affected when the pressure have to be adjusted in order to achieve a certain recovery factor or to improve the operating conditions. In Fig. 9 the specific energy consumption, $S E C_{25}$, is given as function of the recovery ratio, $S_{25}$. It can be observed that there is a slight trend in the decrease of $S E C_{25}$ as the recovery factor increases. An optimum condition in the operation of a RO plant should correspond to minimum requirements in terms of specific energy consumption at a particular applied pressure and recovery ratio [12]. We believe that the achievement of the best operating conditions should be dictated by a more global analysis involving other factors such as the permeate quality, the scaling, the cleaning and maintenance costs, etc.

\section{Conclusions}

Using a simple calculation methodology that combines semi-empirical equations with the classical film theory model, it has been possible to evaluate the performance of an industrial desalination plant which uses spiral wound membranes. For an operational time of 454 days, the normalized water permeability coefficient $\mathrm{A}_{25} / \mathrm{A}_{720}$ decreased by about $7 \%$. This happened because the chemical cleaning of the membranes was not performed during the considered period.

The salt permeability, $B_{2}$, increased significantly during the summer period due mainly to the temperature effect; however, only slight differences were observed in the values of $B_{2}$ at the beginning and end of the period of operation. Even at high salt permeability values, the permeate quality was maintained within specifications according the Portuguese legislation.

The specific energy consumptions obtained in this work are in the range of typical values found in the literature $[11,13]$ and they did not exhibit 
any significant changes during the time period studied.

The approach used allowed a good description of the performance of the plant analyzed and can be applied to the other RO desalination systems operating under similar conditions.

\section{Symbols}

$A \quad-$ Solvent (water) permeability coefficient, $\mathrm{m}^{3} \cdot \mathrm{m}^{-2} \cdot \mathrm{s}^{-1} \cdot \mathrm{bar}^{-1}$

$B_{2} \quad-$ Solute (salt) permeability coefficient, $\mathrm{m}^{3} \cdot \mathrm{m}^{-2} \cdot \mathrm{s}^{-1}$

c - Mass concentration, $\mathrm{kg} \cdot \mathrm{m}^{-3}$

$j \quad-$ Mass flux of the solute, $\mathrm{kg} \cdot \mathrm{m}^{-2} \cdot \mathrm{s}^{-1}$

$J \quad-$ Volumetric flux of the permeate, $\mathrm{m}^{3} \cdot \mathrm{m}^{-2} \cdot \mathrm{s}^{-1}$

$k_{2} \quad-$ Mass transfer coefficient, $\mathrm{m} . \mathrm{s}^{-1}$

$P \quad-\quad$ Pressure drop across membrane

$\Pi \quad$ - Osmotic pressure difference across membrane

$R, R^{\prime} \quad$ - Apparent and real rejection factors

Re - Reynolds number

$S \quad-$ Recovery factor

Sc - Schmidt number

$S E C$ - Specific energy consumption, kW.h.m ${ }^{-3}$

Sh - Sherwood number

$T \quad$ - Temperature, ${ }^{\circ} \mathrm{C}$

\section{Subscripts}

2 - Refers to the salt

21 - Refers to the salt at the feed channels

22 - Refers to the salt at the high pressure surface side of the membrane

23 - Refers to the salt at the permeate channels

$\mathrm{F} \quad-$ Feed

$\mathrm{P} \quad$ - Permeate

\section{Acknowledgement}

The authors thank Mr. Ing. Pimenta de França, President of IGA (Investments and Water Management for Islands of the Madeira Archipelago) and Mr. Ing. Nuno Pereira, Senior Technician at the Porto Santo desalination plant, for their help in this work.

\section{References}

[1] M. Schiffler, Perspectives and challenges for desalination in the 21st century, Desalination, 165 (2004) 1-9.

[2] M. Kuriara, Y. Hiroyuki and N. Takayuki, High recovery/high pressure membrane for brine conversion SWRO process development and its performance, Desalination, 125 (1999) 9-15.

[3] G. Al-Enezi and N. Fawzi, Design considerations of RO units: Case studies, Desalination, 153 (2002) 281-286.

[4] N. Al-Bastaki and A. Abbas, Long-term performance of an industrial water desalination plant, Chem. Eng. Sci., 43 (2004) 555-558.

[5] A. Abbas and N. Al-Bastaki, Performance decline in brackish water filmTec spiral wound RO membranes, Desalination, 136 (2001) 281-286.

[6] C.W. Saltonstall and R.W. Lawrence, Calculation of the expected performance of reverse osmosis plants, Desalination, 42 (1982) 247-253.

[7] M. Taniguchi and S. Kimura, Estimation of transport parameters of RO membranes for seawater desalination, AIChE J., 46(10) (2000) 1967-1971.

[8] A. Sagiv and R. Semiat, Analysis of parameters affecting boron permeation through RO membranes, J. Membr. Sci., 243 (2004) 79-87.

[9] F. Maskan, D. Wiley and P.M. Lloyd, Optimal design of reverse osmosis module networks, AIChE J., 46(5) (2000) 946-954.

[10] P.R. Pinet, Invitation to Oceanography, 2nd ed., Jones and Bartlett, Salsbury, 1999.

[11] T. Manth, M. Gabor and E. Oklejas, Minimizing RO energy consumption under variable conditions of operation, Desalination, 157 (2003) 9-21.

[12] S.A. Avlonitis, Optimization of the design and operation of seawater RO desalination plants, Sep. Sci. Technol., 40 (2005) 2663-2678.

[13] S.A. Avlonitis, Operational water cost and productivity improvements for small-size RO desalination plants, Desalination, 142 (2002) 295-304. 